\title{
Placental malaria is associated with attenuated CD4 T-cell responses to tuberculin PPD 12 months after BCG vaccination
}

Brigitte Walther ${ }^{1 \dagger}$, David JC Miles ${ }^{1,2^{*}+}$, Pauline Waight ${ }^{1,3}$, Melba S Palmero ${ }^{1}$, Olubukola Ojuola ${ }^{1,4}$, Ebrima S Touray ${ }^{1}$, Hilton Whittle ${ }^{1}$, Marianne van der Sande ${ }^{1,5,6}$, Sarah Crozier ${ }^{1,7}$ and Katie L Flanagan ${ }^{1}$

\begin{abstract}
Background: Placental malaria (PM) is associated with prenatal malaise, but many PM+ infants are born without symptoms. As malaria has powerful immunomodulatory effects, we tested the hypothesis that PM predicts reduced T-cell responses to vaccine challenge.

Methods: We recruited healthy PM+ and PM- infants at birth. At six and 12 months, we stimulated PBMCs with tuberculin purified protein derivative (PPD) and compared expression of CD154, IL-2 and IFNy by CD4 T-cells to a negative control using flow cytometry.

We measured the length, weight and head circumference at birth and 12 months.

Results: IL-2 and CD154 expression were low in both groups at both timepoints, without discernable differences. Expression of IFN $\gamma$ was similarly low at 6 months but by 12 months, the median response was higher in PM- than PM + infants $(p=0.026)$. The PM+ infants also had a lower weight $(p=0.032)$ and head circumference $(p=0.041)$ at 12 months, indicating lower growth rates.

At birth, the size and weight of the PM+ and PM- infants were equivalent. By 12 months, the PM+ infants had a lower weight and head circumference than the PM- infants.
\end{abstract}

Conclusions: Placental malaria was associated with reduced immune responses 12 months after immune challenge in infants apparently healthy at birth.

\section{Background}

Plasmodium falciparum malaria is endemic in much of Sub-Saharan Africa and commonly infects the placentas of pregnant women. The overt consequences of placental malaria (PM) include high risk of premature birth and low birth weight [1,2], increased neonatal mortality [3] and infant anaemia [4]. Exposure to PM has been associated with an increased risk for malaria during the first years of life [5].

Placental malaria has been associated with poor cytokine production by T-cells [6,7] and induced tolerance to Plasmodium antigens [8], which may be associated with the induction of regulatory T-cells in PM-exposed

\footnotetext{
* Correspondence: d.miles@bham.ac.uk

† Contributed equally

${ }^{1}$ MRC Laboratories Gambia, PO Box 273, Banjul, Gambia

Full list of author information is available at the end of the article
}

infants [9-11]. These findings are consistent with earlier results that showed that malaria in children led to reduced antibody responses to vaccination with bacterial polysaccharide, glycoconjugate and protein antigens [12-16], and also that prenatal exposure to malaria is associated with relatively low cytokine responses to $P$. falciparum antigens for at least the first three years of life [8].

The effect of malaria may be partly responsible for the observation that in regions of Sub-Saharan Africa where $P$. falciparum malaria is endemic, several vaccines used for routine childhood immunisation are frequently less effective than in high income countries, which was the subject of a recent review [17].

One of the best documented examples is that of the Bacille Calmette-Guérin (BCG) vaccine for tuberculosis, which has demonstrated good protection in most trials
C Biomed Central

() 2012 Walther et al; licensee BioMed Central Ltd. This is an Open Access article distributed under the terms of the Creative Commons Attribution License (http://creativecommons.org/licenses/by/2.0), which permits unrestricted use, distribution, and reproduction in any medium, provided the original work is properly cited. 
carried out in high income countries but little or no protection in trials carried out in low income tropical countries [18]. Mechanisms of protection against tuberculosis have not been defined, but defects in IFN $\gamma$ signalling are strongly predictive of disease so it is likely that the $\mathrm{T}$-cell response plays an important part in protection [19-21].

A possible explanation for the low levels of protection afforded by BCG in sub-Saharan Africa is offered by the finding that BCG does not induce the same level of $\mathrm{T}$ cell IFN $\gamma$ production in Malawian children as it does in British children [22,23].

We hypothesised that the immunomodulatory effects of P. falciparum infection of the placenta extend to immune challenges encountered during the early postnatal period. We conducted a preliminary study using an existing dataset derived from the Sukuta Birth Cohort in The Gambia, which was collected in order to study the development of CD4 T-cell responses to cytomegalovirus (CMV) in early life [24,25], to establish whether there was an association between PM and CD4 $\mathrm{T}$-cell responses to the BCG vaccination.

\section{Methods}

\section{Cohort characteristics}

Healthy infants were recruited from the maternity ward of Sukuta Health Centre, following written informed consent from both parents. Sukuta Health Centre serves a low income, peri-urban community in The Gambia. Malaria transmission rates are at their highest during and immediately after the wet season, giving rise to a distinct malaria season from August to December [25]. Recruitment took place from January to August, 2002.

Infants were recruited at birth, and the cohort was restricted to healthy infants by excluding infants with a birthweight below $2.0 \mathrm{~kg}$, infants born from pregnancies with complications that required hospital admission and infants with congenital abnormalities. Twins were also excluded.

From the existing dataset, we identified a PM+ group consisting of all infants exposed to placental malaria whose response to PPD had been measured at either six (23-30 weeks) or 12 months (46-58 weeks) or both. We then identified a PM- group of all infants whose response to PPD had been measured at the same ages, and whose placentas showed no signs of malarial infection.

At birth, the APGAR score at 5 min was recorded. Babies were weighed, the length was measured with a measuring board, and a tape measure was used to measure the head and mid-upper arm circumferences. The weight, length and head circumference were measured again at 12 months.
All infants were immunised intradermally with BCG within $24 \mathrm{~h}$ of birth according to the Gambian expanded program of immunisation.

Mothers were requested to bring infants to the clinic if they became ill at any point during follow up, where treatment was provided and details of the illnesses recorded.

The study was approved by the Gambia Government/ MRC Laboratories Joint Ethics Committee.

\section{Intracytoplasmic cytokine staining}

The PBMCs were isolated by density gradient centrifugation using lymphoprep (Axis-Shield POC AS, Oslo, Norway) and resuspended at $2 \times 10^{6}$ cells ml $^{-1}$ in R10F $(90 \%$ $\mathrm{v} / \mathrm{v}$ RPMI-1640 containing $100 \mathrm{U} \mathrm{ml}^{-1}$ penicillin plus 100 $\mu \mathrm{g} \mathrm{ml}^{-1}$ streptomycin, $10 \% \mathrm{v} / \mathrm{v}$ fetal bovine serum) and treated with either $10 \mu \mathrm{g} \mathrm{ml}^{-1}$ of the RT49 preparation of tuberculin purified protein derivative (PPD) (Statens Serum Institut, Copenhagen, Denmark), $10 \mu \mathrm{g} \mathrm{ml}^{-1}$ lysed CMV-infected human dermal fibroblast cells (Virusys, Taneytown, MD, USA), or $10 \mu \mathrm{g} \mathrm{ml}^{-1}$ normal human dermal fibroblast lysate (NHDF) (Virusys) [26] as a negative control, as required by the CMV study [24]. After $2 \mathrm{~h}$ at $37^{\circ} \mathrm{C}$ in a $5 \%$ carbon dioxide atmosphere, cytokine secretion was inhibited with $10 \mu \mathrm{g} \mathrm{ml}^{-1}$ brefeldin A (Sigma, Natick, MA, USA) and the PBMCs were incubated for a further $16 \mathrm{~h}$. The PBMCs were concentrated by centrifugation, permeabilised using FACSperm II solution (BD Biosciences, Franklin Lakes, NJ, USA), and stained with PerCP-conjugated anti-CD4 antibodies, FITC-conjugated anti-IFN- $\gamma$ antibodies, PE-conjugated anti-CD154 antibodies, and APC-conjugated anti-IL-2 antibodies. All antibodies were obtained from BD. The stained cells were stored in $2 \% \mathrm{v} / \mathrm{v}$ formalin in phosphate-buffered saline at $4^{\circ} \mathrm{C}$ and as many cells as possible were acquired on a four-color FACScalibur (BD), and analyzed using FCS Express (De Novo Software, Los Angeles, CA, USA). CD4 T-cells were identified as having high levels of staining for CD4 (median number of CD4 T-cells 28,506, IQR 9,899-61,453). Cells expressing markers of interest were identified by setting gates on negative control cells to identify non-responding cells, and applying the same gates to the PPD-stimulated cells (Figure 1). The PPD and $\mathrm{CMV}$-specific responses were defined as the percentage of CD4 T-cells expressing each marker among the PPD-treated cells after subtraction of the percentage of CD4 T-cells expressing each marker among the negative control cells.

\section{Diagnosis of placental malaria}

PM was diagnosed from a $1 \mathrm{~cm} \times 2 \mathrm{~cm} \times 2 \mathrm{~cm}$ biopsy of the placenta that was stained with haematoxylin and eosin and examined under a light microscope by two 

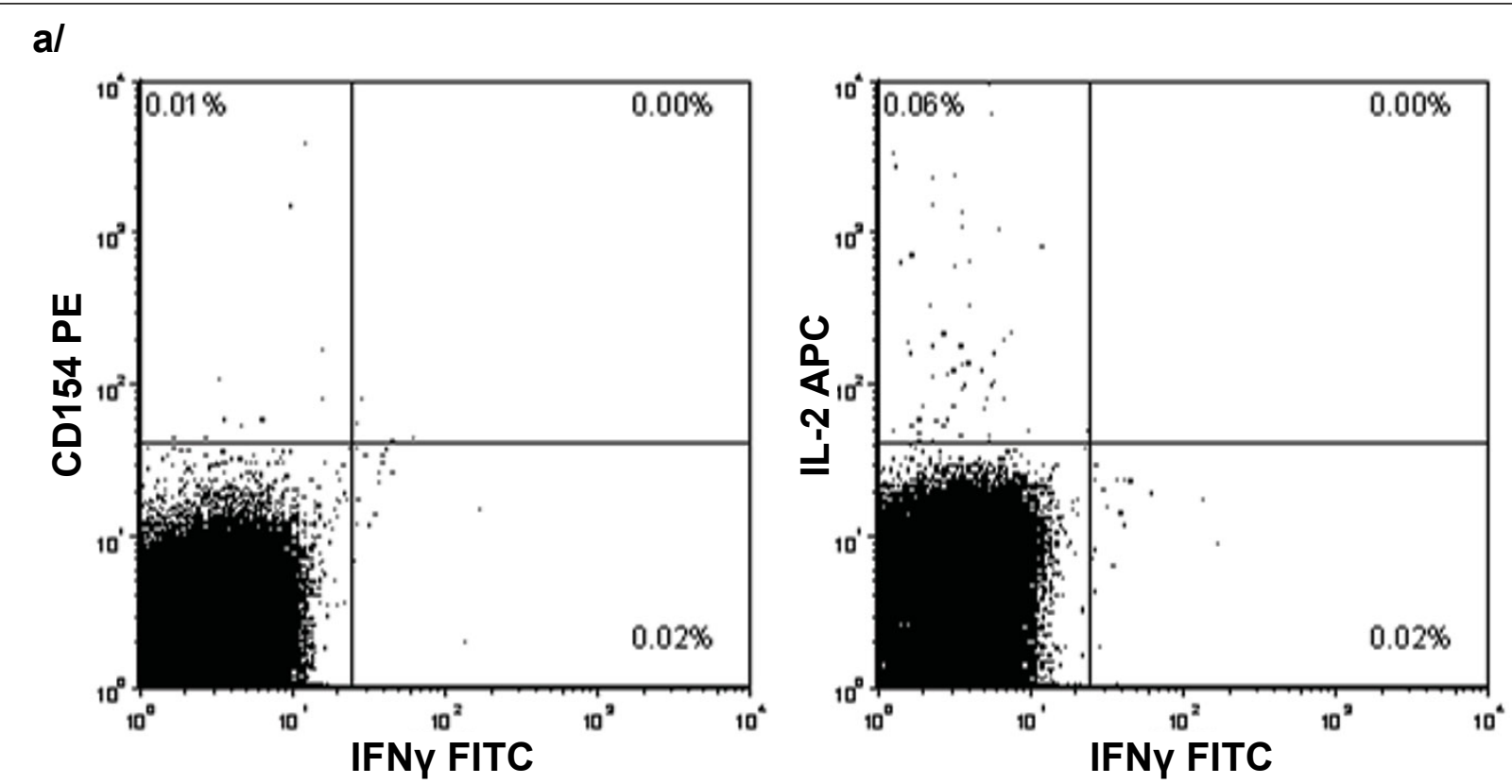

b/
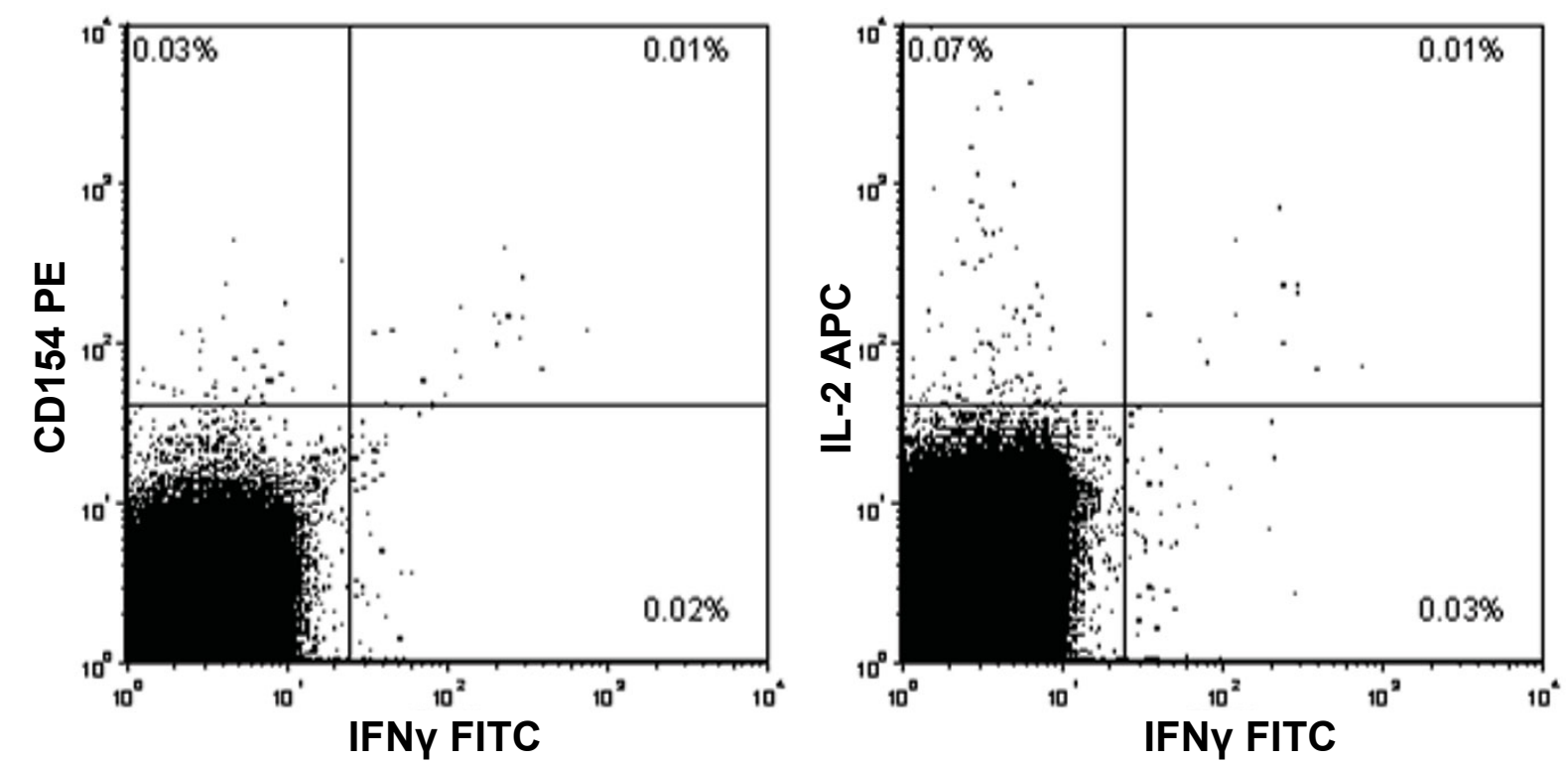

Figure 1 Gating of CD4 T-cells expressing IFN $\gamma$, IL-2 and CD154. Following selection of lymphocytes by forward and side scatter characteristics and CD4 T-cells by gating on high expression of CD4, quadrant gates were set on a/the negative control sample and then applied to b/the PPD-stimulated sample. Sample selected as representative as it has the median CD154 response among PM- infants at 12 months.

trained diagnosticians [10]. If evidence of malaria infection was found, it was classified as past, acute or chronic infection [27].

\section{Statistical analysis}

Data on PPD responses were available from 24 infants at 6 months, of whom five were PM+ at birth. Data were available from 35 infants at 12 months, of whom seven were $\mathrm{PM}+$ at birth. The low numbers made it impossible to analyse acute, chronic and past infection separately, so infants with any presentation of PM were classified as $\mathrm{PM}+$ and compared with PM- infants.

Mann-Whitney U tests were used to compare measurements of weight, size, APGAR score and CD4 
responses to PPD. Statistical analysis were performed with Stata 9.1 (StataCorp LP, College Station, TX, USA) and MINITAB 14 (Minitab inc, State College, PA, USA).

\section{Results}

\section{Clinical characteristics}

The size, weight and APGAR scores of PM+ and PMinfants were equivalent at birth (Table 1). By 12 months of age, the median weight and head circumference of the PM- infants were greater than those of the PM+ infants, although there was no discernable difference in length (Table 2).

Of the five PM+ infants sampled at six months, two were diagnosed with acute infection, one with chronic infection and two with past infection. Of the seven PM+ infants sampled at 12 months, three had acute infection, one had chronic infection and three had past infection.

During the follow-up period, malaria infections were diagnosed in three of the 28 PM- infants and none of the seven $\mathrm{PM}+$ infants, which was not a significant difference.

\section{Less CD4 T-cells produced IFN $\gamma$ in response to PPD following exposure to placental malaria}

At 6 months, very few PPD-specific IFN $\gamma$-producing CD4 T-cells were found in any of the infants, and there were no significant differences in responses between PM + (median 0.002\%, IQR -0.008; 0.007\%) and PM- (median $0.005 \%$, IQR $0.001 ; 0.011 \%$ ) groups. By 12 months of age, most of the PM- infants had at least some PPDspecific response, and the proportion of PPD-specific IFN $\gamma$-producing $\mathrm{CD} 4 \mathrm{~T}$-cells was significantly higher in PM- (median 0.007\%, IQR 0.002; 0.037) than PM+ infants (median $0.000 \%$, IQR $-0.002 ; 0.002 \%)(p=0.026)$ (Figure 2).

\section{Few CD4 T-cells responded to PPD by producing IL-2 or CD154}

The median PPD-specific IL-2 and CD154 responses of both $\mathrm{PM}+$ and PM- infants were negative at 6 months, indicating that percentages of responding PPD-treated cells were below negative control levels. By 12 months the median PPD-specific response of PM- infants was positive, albeit very low, for IL-2 (median 0.002\%, IQR -0.002; 0.009) and CD154 (median 0.003\%, IQR -0.026; 0.009). Median responses of $\mathrm{PM}+$ infants remained negative and very close to zero, but there was no significant difference between PM+ and PM- groups.

\section{No association between PM and responses to CMV}

As the majority of the infants were infected with CMV, we also compared the CD4 $\mathrm{T}$-cell responses to $\mathrm{CMV}$ lysate between PM- and PM+ infants. The numbers available were $5 \mathrm{PM}+$ and $20 \mathrm{PM}$ - at 6 months, and 5 $\mathrm{PM}+$ and 24 PM- at 12 months.

We found no significant differences in the percentages of CD4 T-cells expressing IFN $\gamma$, IL-2 or CD154 between $\mathrm{PM}+$ and PM- infants, either at six or 12 months of age (data not shown).

\section{Discussion}

Our principal finding is that placental malaria predicted a relatively weak IFN $\gamma$ response to PPD a year after birth, which was also a year after the administration of the BCG vaccine. No difference was detectable at 6 months, probably because of the low response in both groups.

By contrast, we did not find an association between $\mathrm{PM}$ and responses to CMV. There are distinct differences in the presentation of BCG and CMV, as the BCG vaccine is administered within $24 \mathrm{~h}$ of birth and is present for a limited period of time. Gambian infants are usually infected with CMV several weeks after birth [28], after which it establishes a persistent infection so that the host is exposed to CMV antigens for the rest of their life [29]. The contrast between the associations with BCG and CMV suggests two mutually compatible explanations. The first is that the influence of PM on the response to $\mathrm{BCG}$ is stronger because the exposure to BCG occurred chronologically closer to the exposure to the exposure to placental malaria. The other is that the persistently high antigen exposure in CMV-infected infants drove the immune response to overcome any deleterious influence of PM.

The lack of effect on responses to CMV contrasts with earlier findings that malaria episodes are associated with

Table 1 Size, weight and APGAR scores of PM+ and PM- infants at birth

\begin{tabular}{lllll}
\hline & & PM+ $(\mathbf{n}=7)$ & \multicolumn{1}{c}{ PM- $(\mathbf{n}=\mathbf{2 8})$} \\
\hline Parameter & Median & IQR & Median & IQR \\
\hline APGAR score & 9 & $9-10$ & 9 & $9-10$ \\
\hline Birthweight $(\mathrm{kg})$ & 2.95 & $2.73-3.11$ & 2.93 & $2.70-3.40$ \\
\hline Length $(\mathrm{cm})$ & 49 & $48-51$ & 49 & $48-50$ \\
\hline Head circumference $(\mathrm{cm})$ & 34 & $33-34$ & 34 & $33-35$ \\
\hline Mid-upper arm circumference $(\mathrm{cm})$ & 10.6 & $9.7-11.0$ & 9.8 & $9.6-10.5$ \\
\hline
\end{tabular}

None of the differences were significant 
Table 2 Weight, length and head circumference measured at 12 months of age

\begin{tabular}{llllll}
\hline & & PM+ $(\mathbf{n}=\mathbf{7})$ & PM- $(\mathbf{n}=\mathbf{2 8})$ & P \\
\hline Parameter & Median & IQR & Median & IQR & \\
\hline Weight $(\mathrm{kg})$ & 8 & $7.30-8.46$ & 9.14 & $8.05-10.18$ & 0.032 \\
\hline Length $(\mathrm{cm})$ & 72.8 & $71.0-74.4$ & 73.5 & $72.5-75.4$ & NS \\
\hline Head circumference $(\mathrm{cm})$ & 44.5 & $43.5-45.0$ & 45.5 & $44.6-46.38$ & 0.041 \\
\hline
\end{tabular}

Comparisons by Mann-Whitney $\mathrm{U}$ test. NS indicates non-significant

low responses to another persistent herpesvirus, EpsteinBarr virus (EBV), and also with higher EBV viral loads [30-32], implying poor immune control of viral replication. However, our study differs substantially from the studies that generated these findings as apart from the fact that the natural histories of CMV and EBV infection are very different, the children in our study were younger than most of those in the previous studies. Further, the previous studies were on children who either had a recent malaria episode or were frequently infected, while the infants in our cohort were exposed to PM and very few developed malaria in the subsequent year, implying little or no exposure to $P$. falciparum.

We have previously reported that in BCG-vaccinated infants below 12 months, few CD4 T-cells produce IFN $\gamma$ in response to PPD [33], so it is likely that differences associated with PM were simply undetectable until the $\mathrm{CD} 4 \mathrm{~T}$-cells of the infants were producing enough IFN $\gamma$ for a difference to be apparent.
The numbers were too small to analyse for the effects of acute, chronic and past PM. However, the relative proportions of the three types were similar in the infants sampled at six and 12 months, making it unlikely that the appearance of a difference at 12 months was due to a difference in the type of PM among the PM+ infants.

The sizes and weights of infants at birth in the PM+ and PM- groups were comparable, so we could exclude the confounding effects of premature birth and low birth weight which are well described for PM $[1,2]$. The exclusion criterion of low birthweight also ruled out the effect of prenatal undernutrition, which is associated with poor immune development $[34,35]$ and while we have previously found an association between PM and congenital cytomegalovirus infection [36], we found no evidence that congenital cytomegalovirus modulated the responses of CD4 T-cells to PPD [24] in a much larger and more powerful study.

Testing for HIV was not carried out, but a survey carried out in the nearby town of Serrekunda from 2000 to

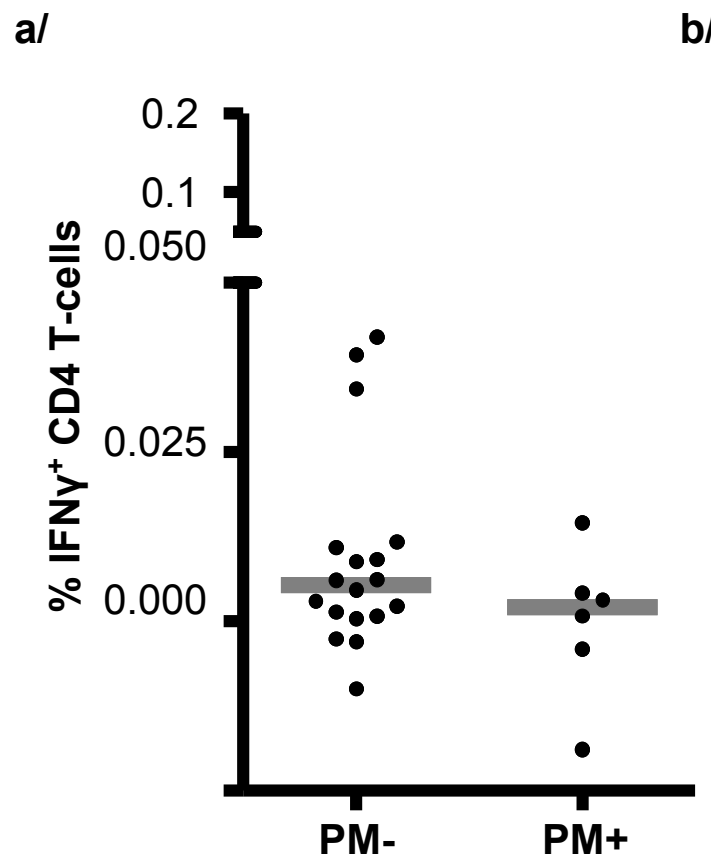

b/

$p=0.026$

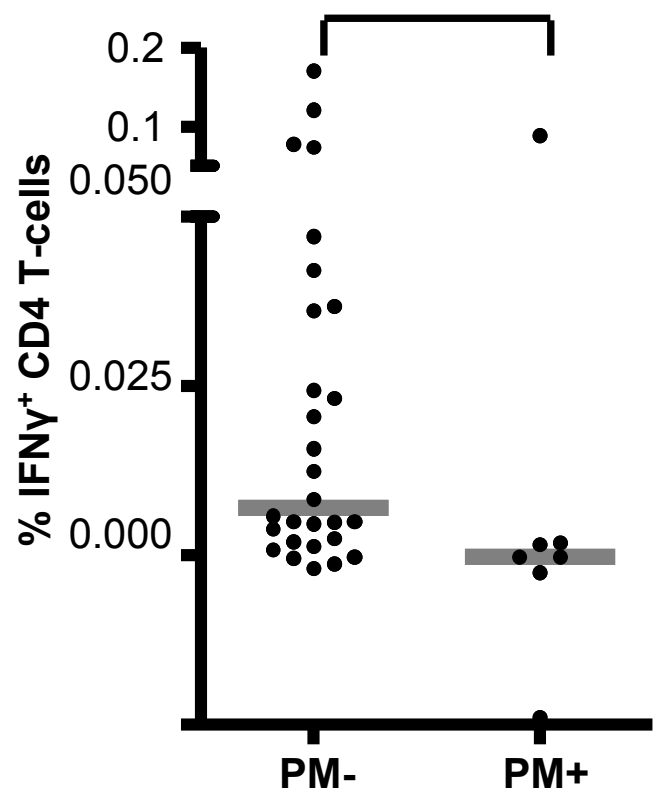

Figure 2 Percentages of CD4 T-cells that expressed IFN $\gamma$ at a/6 months and b/12 months compared by placental malaria (PM) status of the infant. Bars indicate medians. Statistical comparisons by Mann-Whitney $U$ test. 
2001 found a prevalence of $1.0 \%$ among pregnant women [37], and a recent screen of women in Sukuta confirmed the rates to be $<1 \%$ (unpublished), thus HIV was unlikely to be a serious confounder.

Helminth infection has been shown to modulate immune responses to mycobacterial antigens in BCGvaccinated children [38-40], but we found that intestinal helminth infections are not endemic in infants in the Sukuta area after a screen of fecal samples collected at 12 months of age (unpublished). However, the possibility has been raised that helminth infection during pregnancy may reduce the IFN $\gamma$ response to PPD [41], which we cannot eliminate as we did not screen the mothers for intestinal infections.

By 12 months of age, the PM+ infants were slightly smaller than the PM- infants. As there were no differences at birth, the difference at 12 months implies that PM was associated with reduced growth, which concurs with our findings from the entire cohort from which infants were selected for the analysis presented here [25]. Similarly, the differences in IFN $\gamma$ response emerged between 6 and 12 months, suggesting that PM was predictive of deleterious effects that remained present 12 months after birth.

Although no correlate of protection to tuberculosis has been identified, the ability to generate IFN $\gamma$-producing T-cells has been shown to be important, as defects in IFN $\gamma$ signalling lead to a high susceptibility to tuberculosis disease [19-21]. While it is possible that the reduced number of IFN $\gamma$-producing cells indicated a shift in response profile, rather than an overall loss of $\mathrm{T}$-cell response, it is still likely that a reduced number of IFN $\gamma$-producing CD4 T-cells represents a reduced level of protection.

While we detected an association between PM and reduced immune response to BCG vaccination at birth, the scope of the study did not extend to establishing whether there was a direct causal link. Although PM makes infants more susceptible to subclinical P. falciparum infection and episodes of malaria $[5,8,42]$, it is unlikely that the lower responses of PM+ infants were due to the immunosuppressive effect of repeated malaria episodes $[43,44]$ as we did not find a higher rate of malarial disease in PM + infants. While we could not exclude all possible confounders, no effect that we were able to measure showed any association with reduced responses other than exposure to PM.

\section{Conclusions}

The fact that an association between PM and reduced immune responses was detectable with such low numbers suggests a strong association between PM and reduced CD4 T-cell response. As subclinical PM is common in Sub-Saharan Africa, a study on a large enough scale to confirm our findings and investigate the mechanism may yield results that are important for infant health in the region.

\section{Acknowledgements}

We thank the following staff involved in the care and follow up of the Sukuta birth cohort: Omar Badjie, Fatou Bah, Saihou Bobb, Janko Camara, Sulayman Colley, Isatou Drammeh, Mam Maram Drammeh, Baboucarr Jobe, Momodou Jobe, Albert Magnusen, John Mendy, Ngui Ndow, Faalou Njie, Bala Musa Sambou, Sarjo Sanneh, and Mamadi Sidibeh. Akram Zaman, Paul Snell, and David Jeffries helped with data handling. We are extremely grateful for the support of Sally Savage of the Sukuta Government Hospital and Abi Khan of the Western Division Health Team. We are also indebted to the study families and their children. The study was funded by MRC (UK).

\section{Author details}

'MRC Laboratories Gambia, PO Box 273, Banjul, Gambia. ${ }^{2}$ Malawi-LiverpoolWellcome Trust Clinical Research Programme, PO Box 30096, Chichiri,

Blantyre 3, Malawi. ${ }^{3}$ Immunisation Department, Health Protection Agency Centre for Infections, London, UK. ${ }^{4}$ Department of Pediatrics, Bronx Lebanon Hospital Center, 1650 Selwyn Avenue, Bronx, New York, USA. ${ }^{5}$ Epidemiology and Surveillance Unit, Centre for Infectious Diseases Control, National Institute for Public Health and the Environment, Bilthoven, The Netherlands. ${ }^{6} J u l i u s$ Centre, University Medical Centre Utrecht, Utrecht, The Netherlands. ${ }^{7}$ MRC Epidemiology Resource Centre, University of Southampton,

Southampton General Hospital, Southampton, UK.

\section{Authors' contributions}

BW, DJCM, MvdS and HW conceived and designed the study. DJCM, MvdS, OO, EST, KLF and MSP implemented the study and collected the data. BW, DJCM, PW and SC interpreted and analysed the data. DJCM and BW drafted the manuscript. All authors critically reviewed and approved the final manuscript.

\section{Competing interests}

The authors declare that they have no competing interests.

Received: 7 November 2011 Accepted: 14 January 2012 Published: 14 January 2012

\section{References}

1. Sullivan A, Nyirenda T, Cullinan T, Taylor T, Harlow S, James S, Meshnick S: Malaria infection during pregnancy: intrauterine growth retardation and preterm delivery in Malawi. J Infect Dis 1999, 179(6):1580-1583.

2. Luxemburger C, McGready R, Kham A, Morison L, Cho T, Chongsuphajaisiddhi T, White N, Nosten F: Effects of malaria during pregnancy on infant mortality in an area of low malaria transmission. Am J Epidemiol 2001, 154(5):459-465.

3. Garner P, Gülmezoglu A: Drugs for preventing malaria-related illness in pregnant women and death in the newborn. Cochrane Database Syst Rev 2003, 1: CD000169.

4. Le Cessie S, Verhoeff F, Mengistie G, Kazembe P, Broadhead R, Brabin B: Changes in haemoglobin levels in infants in Malawi: effect of low birth weight and fetal anaemia. Arch Dis Child Fetal Neonatal Ed 2002, 86(3): F182-F187.

5. Le Hesran J, Cot M, Personne P, Fievet N, Dubois B, Beyemé M, Boudin C, Deloron P: Maternal placental infection with Plasmodium falciparum and malaria morbidity during the first 2 years of life. Am J Epidemiol 1997, 146(10):826-831.

6. Broen K, Brustoski K, Engelmann I, Luty A: Placental Plasmodium falciparum infection: causes and consequences of in utero sensitization to parasite antigens. Mol Biochem Parasitol 2007, 151(1):1-8.

7. Ismaili J, van der Sande M, Holland M, Sambou I, Keita S, Allsopp C, Ota M, McAdam K, Pinder M: Plasmodium falciparum infection of the placenta affects newborn immune responses. Clin Exp Immunol 2003, 133(3):414-421.

8. Malhotra I, Dent A, Mungai P, Wamachi A, Ouma J, Narum D, Muchiri E, Tisch D, King C: Can prenatal malaria exposure produce an immune 
tolerant phenotype? A prospective birth cohort study in Kenya. PLoS Med 2009, 6(7):e1000116.

9. Bisseye C, van der Sande M, Morgan W, Holder A, Pinder M, Ismaili J: Plasmodium falciparum infection of the placenta impacts on the T helper type $1(\mathrm{Th} 1) / \mathrm{Th} 2$ balance of neonatal T cells through $\mathrm{CD} 4^{+} \mathrm{CD} 25^{+}$ forkhead box $\mathrm{P3}^{+}$regulatory T cells and interleukin-10. Clin Exp Immunol 2009, 158(3):287-293.

10. Flanagan $K$, Halliday A, Burl S, Landgraf $K$, Jagne $Y$, Noho-Konteh F, Townend J, Miles D, van der Sande M, Whittle $H$, et al: The effect of placental malaria infection on cord blood and maternal immunoregulatory responses at birth. Eur J Immunol 2010, 40(4):1-11.

11. Brustoski K, Möller U, Kramer M, Hartgers F, Kremsner P, Krzych U, Luty A: Reduced cord blood immune effector-cell responsiveness mediated by $\mathrm{CD}^{+}$cells induced in utero as a consequence of placental Plasmodium falciparum infection. J Infect Dis 2006, 193(1):146-154.

12. McGregor I, Barr M: Antibody response to tetanus toxoid inoculation in malarious and non-malarious Gambian children. Trans R Soc Trop Med Hyg 1962, 56(5):364-367.

13. Greenwood B, Bradley-Moore A, Bryceson A, Palit A: Immunosuppression in children with malaria. Lancet 1972, 299(7743):169-172

14. Williamson W, Greenwood B: Impairment of the immune response to vaccination after acute malaria. Lancet 1978, 311(8078):1328-1329.

15. Bradley-Moore A, Greenwood B, Bradley A, Bartlett A, Bidwell D, Voller A, Craske J, Kirkwood B, Gilles H: Malaria chemoprophylaxis with chloroquine in young Nigerian children. II. Effect on the immune response to vaccination. Ann Trop Med Parasitol 1985, 79(6):563-573.

16. Usen S, Milligan P, Ethevenaux C, Greenwood B, Mulholland K: Effect of fever on the serum antibody response of Gambian children to Haemophilus influenzae type $\mathrm{b}$ conjugate vaccine. Pediatr Infect Dis $J$ 2000, 19(5):444-449.

17. Cunnington A, Riley E: Suppression of vaccine responses by malaria: insignificant or overlooked? Expert Rev Vaccines 2010, 9(4):409-429.

18. Wilson ME, Fineberg HV, Colditz GA: Geographic latitude and the efficacy of bacillus Calmette-Guérin vaccine. Clin Infect Dis 1995, 20(4):982-991.

19. Newport M, Huxley C, Huston S, Hawrylowicz C, Oostra B, Williamson R, Levin $\mathrm{M}$ : A mutation in the interferon-gamma-receptor gene and susceptibility to mycobacterial infection. N Engl J Med 1996 335(26):1941-1949

20. Dorman S, Holland S: Mutation in the signal-transducing chain of the interferon- $\gamma$ receptor and susceptibility to mycobacterial infection. J Clin Invest 1998, 101(11):2364-2369.

21. Kampmann B, Hemingway C, Stephens A, Davidson R, Goodsall A, Anderson S, Nicol M, Schölvinck E, Relman D, Waddell S, et al: Acquired predisposition to mycobacterial disease due to autoantibodies to IFN- $\gamma$. J Clin Invest 2005, 115(9):2480-2488.

22. Black G, Weir R, Floyd S, Bliss L, Warndorff D, Crampin A, Ngwira B, Sichali L, Nazareth B, Blackwell J, et al: BCG-induced increase in interferon-gamma response to mycobacterial antigens and efficacy of BCG vaccination in Malawi and the UK: two randomised controlled studies. The Lancet 2002, 359(9315):1393-1401

23. Lalor M, Ben-Smith A, Gorak-Stolinska P, Weir R, Floyd S, Blitz R, Mvula H, Newport M, Branson K, McGrath N, et al: Population differences in immune responses to Bacille Calmette-Guérin vaccination in infancy. J Infect Dis 2009, 199(6):795-800.

24. Miles D, van der Sande M, Kaye S, Crozier S, Ojuola O, Sanneh M, Touray E, Waight $\mathrm{P}$, Rowland-Jones $\mathrm{S}$, Whittle $\mathrm{H}$, et al: $\mathrm{CD}^{+} \mathrm{T}$ cell responses to cytomegalovirus in early life: a prospective birth cohort study. I Infect Dis 2008, 197(5):658-662.

25. Walther B, Miles D, Crozier S, Waight P, Palmero M, Ojuola O, Touray E, van der Sande $\mathrm{M}$, Whittle $\mathrm{H}$, Rowland-Jones $\mathrm{S}$, et al: Placental malaria is associated with reduced early life weight development of affected children independent of low birth weight. Malar J 2010, 9(1):16

26. Hayes $\mathrm{K}$, Alford C, Britt W: Antibody response to virus-encoded proteins after cytomegalovirus mononucleosis. J Infect Dis 1987, 156(4):615-621.

27. Ismail M, Ordi J, Menendez C, Ventura P. Aponte J, Kahigwa E, Hirt R, Cardesa A, Alonso P: Placental pathology in malaria: a histological, immunohistochemical, and quantitative study. Hum Pathol 2000, 31(1):85-93.

28. Kaye $S$, Miles D, Antoine P, Burny W, Ojuola O, Kaye P, Rowland-Jones $S$, Whittle $H$, van der Sande M, Marchant A: Virological and immunological correlates of mother to child transmission of cytomegalovirus in The Gambia. J Infect Dis 2008, 197(9):1307-1314.

29. Pass RF: Epidemiology and transmission of cytomegalovirus. J Infect Dis 1985, 152(2):243-248

30. Njie R, Bell A, Jia H, Croom-Carter D, Chaganti S, Hislop A, Whittle H, Rickinson A: The effects of acute malaria on Epstein-Barr virus (EBV) load and EBV-specific T cell immunity in Gambian children. J Infect Dis 2009, 199(1):31-38

31. Moormann A, Chelimo K, Sumba O, Lutzke M, Ploutz-Snyder R, Newton D, Kazura J, Rochford R: Exposure to holoendemic malaria results in elevated Epstein-Barr virus loads in children. J Infect Dis 2005, 191(8):1233-1238.

32. Moormann A, Chelimo K, Sumba P, Tisch D, Rochford R, Kazura J: Exposure to holoendemic malaria results in suppression of Epstein-Barr virusspecific T cell immunosurveillance in Kenyan children. J Infect Dis 2007, 195(6):799-808.

33. Miles D, van der Sande M, Crozier S, Ojuola O, Palmero M, Sanneh M, Touray E, Rowland-Jones S, Whittle H, Ota M, et al: Effect of Antenatal and Postnatal environment on CD4 T-cell Responses to BCG in healthy Gambian infants. Clin Vaccine Immunol 2008, 15(6):995-1002.

34. Moore S, Jalil F, Ashraf R, Szu S, Prentice A, Hanson L: Birth weight predicts response to vaccination in adults born in an urban slum in Lahore, Pakistan. Am J Clin Nutr 2004, 80(2):453-459.

35. McDade T, Beck M, Kuzawa C, Adair L: Prenatal undernutrition, postnatal environments, and antibody response to vaccination in adolescence. Am J Clin Nutr 2001, 74(4):543-548.

36. van der Sande M, Kaye S, Miles D, Waight P, Jeffries D, Ojuola O, Palmero M, Pinder M, Ismaili J, Flanagan K: Risk factors for and clinical outcome of congenital cytomegalovirus infection in a peri-urban westAfrican birth cohort. PLOS ONE 2007, 2(6):e492.

37. Schim van der Loeff M, Sarge-Njie R, Ceesay S, Awasana A, Jaye P, Sam O, Jaiteh $\mathrm{K}$, Cubitt D, Milligan P. Whittle H: Regional differences in HIV trends in The Gambia: results from sentinel surveillance among pregnant women. AIDS 2003, 17(12):1841-1846.

38. Malhotra I, Mungai P, Wamachi A, Kioko J, Ouma J, Kazura J, King C: Helminth- and Bacillus Calmette-Guérin-induced immunity in children sensitized in utero to filariasis and schistosomiasis. J Immunol 1999, 162(11):6843-6848

39. Wammes L, Hamid F, Wiria A, de Gier B, Sartono E, Maizels R, Luty A, Fillié $Y$, Brice $G$, Supali $T$, et al: Regulatory $T$ cells in human geohelminth infection suppress immune responses to BCG and Plasmodium falciparum . Eur J Immunol 2010, 40(2):437-442.

40. Elias D, Britton S, Aseffa A, Engers H, Akuffo H: Poor immunogenicity of BCG in helminth infected population is associated with increased in vitro TGF- $\beta$ production. Vaccine 2008, 26(31):3897-3902.

41. LaBeaud A, Malhotra I, King M, King C, King C: Do antenatal parasite infections devalue childhood vaccination? PLoS Negl Trop Dis 2009, 3(5): e442.

42. Schwarz N, Adegnika A, Breitling L, Gabor J, Agnandji S, Newman R, Lell B, Issifou S, Yazdanbakhsh M, Luty A, et al: Placental malaria increases malaria risk in the first 30 months of life. Clin Infect Dis 2008, 47(8):1017-1025.

43. Urban B, Ferguson D, Pain A, Willcox N, Plebanski M, Austyn J, Roberts D: Plasmodium falciparum-infected erythrocytes modulate the maturation of dendritic cells. Nature 1999, 400(6739):73-77.

44. Ho M, Webster H, Green B, Looareesuwan S, Kongchareon S, White N: Defective production of and response to IL-2 in acute human falciparum malaria. J Immunol 1988, 141(8):2755-2759.

\section{Pre-publication history}

The pre-publication history for this paper can be accessed here: http://www.biomedcentral.com/1471-2334/12/6/prepub

doi:10.1186/1471-2334-12-6

Cite this article as: Walther et al: Placental malaria is associated with attenuated CD4 T-cell responses to tuberculin PPD 12 months after BCG vaccination. BMC Infectious Diseases 2012 12:6. 